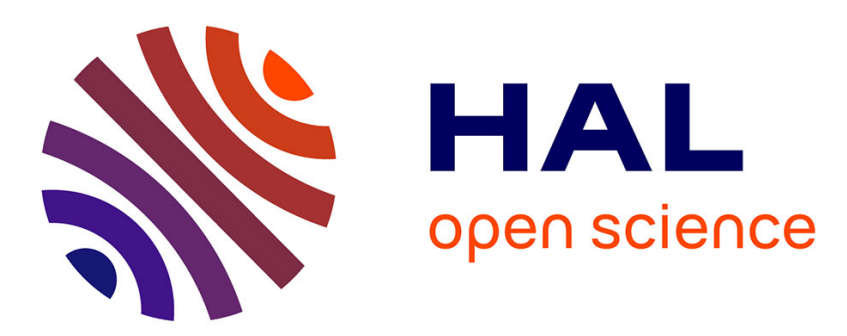

\title{
Isolation at physiological temperature of detergent-resistant membranes with properties expected of lipid rafts: the influence of buffer composition
}

Xi Chen, Angela Jen, Alice Warley, M Jayne Lawrence, Peter J Quinn, Roger J Morris

\section{To cite this version:}

Xi Chen, Angela Jen, Alice Warley, M Jayne Lawrence, Peter J Quinn, et al.. Isolation at physiological temperature of detergent-resistant membranes with properties expected of lipid rafts: the influence of buffer composition. Biochemical Journal, 2008, 417 (2), pp.525-533. 10.1042/BJ20081385 . hal00479065

\section{HAL Id: hal-00479065 https://hal.science/hal-00479065}

Submitted on 30 Apr 2010

HAL is a multi-disciplinary open access archive for the deposit and dissemination of scientific research documents, whether they are published or not. The documents may come from teaching and research institutions in France or abroad, or from public or private research centers.
L'archive ouverte pluridisciplinaire HAL, est destinée au dépôt et à la diffusion de documents scientifiques de niveau recherche, publiés ou non, émanant des établissements d'enseignement et de recherche français ou étrangers, des laboratoires publics ou privés. 


\title{
Isolation at physiological temperature of detergent-resistant membranes with properties expected of lipid rafts: the influence of buffer composition·
}

\author{
Xi CHEN*,3, Angela JEN*, Alice WARLEY $\dagger$, M. Jayne LAWRENCE $\$$, Peter J QUINN $\$$ and Roger J \\ MORRIS $*, 1$ \\ ${ }^{*}$ Wolfson Centre for Age-related Disease, ${ }^{\dagger}$ Centre for Ultrastructural Imaging, ${ }^{\ddagger}$ Pharmaceutical Sciences Research \\ Division, King's College London. London UK. \\ Running Title: $\quad$ Isolation of DRMs at $37^{\circ} \mathrm{C}$
}

\begin{abstract}
The failure of most non-ionic detergents to release patches of detergent-resistant membrane (DRM) at $37^{\circ} \mathrm{C}$ undermines the claim that DRMs consist of lipid nanodomains that exist in an $\mathrm{L}_{\mathrm{o}}$ (liquid ordered) phase on the living cell surface. We show here that inclusion of cations $\left(\mathrm{Mg}^{2+}, \mathrm{K}^{+}\right)$to mimic the intracellular environment stabilises membranes during solubilization sufficiently to allow the isolation of DRMs at $37^{\circ} \mathrm{C}$, using either Triton X-100 or Brij 96. These DRMs are sensitive to chelation of cholesterol, maintain outsideout orientation of membrane glycoproteins, have prolonged (18 hour) stability at $37^{\circ} \mathrm{C}$, and are vesicles or sheets up to 150-200 nm diameter. DRMs containing glycosylphosphatidylinositol (GPI)-anchored proteins PrP and Thy- 1 can be separated by immunoaffinity isolation, in keeping with their separate organization and trafficking on the neuronal surface. Thy- 1 but not PrP DRMs are associated with actin. Electron microscope (EM) immunohistochemistry shows most PrP, and some Thy-1, to be clustered on DRMs, again maintaining their organization on the neuronal surface. For DRMs labelled for either protein, the bulk of the surface of the DRM is not labelled, indicating that the GPI-anchored protein is a minor component of its lipid domain. These $37^{\circ} \mathrm{C}$ DRMs thus have properties expected of raft membrane, yet pose more questions about how proteins are organized within these nanodomains.
\end{abstract}

Key Words: lipid rafts; detergent resistant membrane; non-ionic detergent; cholesterol; prion protein; Thy-1

\section{INTRODUCTION}

Lipid rafts are postulated to be nanodomains within the cell surface membrane, formed by local condensation of cholesterol with saturated lipids to form distinct patches of $\mathrm{L}_{\mathrm{o}}$ phase within the general fluid 'sea' of liquid disordered $\left(\mathrm{L}_{\mathrm{d}}\right)$ phase lipids. Proteins partition differentially into either of these two lipid phases, providing a lipid-based organization of surface proteins [1].

A major biochemical aim has been to isolate these distinctive membrane nanodomains to allow their composition and structure to be determined, and hence their mechanism in directing signalling and other cellular functions to be understood. The most common approach has been to exploit the observation that the fluid $L_{d}$ phase of the membrane can be fully solubilized by non-ionic detergents at $4^{\circ} \mathrm{C}$, leaving $\mathrm{L}_{\mathrm{o}}$ phase membrane, whose ordered structure excludes these surfactants, to float as light detergent-resistant membrane (DRM) in density gradient ultracentrifugation [2-4].

The extent to which DRMs represent the composition of 'rafts' on living cells has been repeatedly challenged (e.g. $[5,6])$. A general problem is that DRMs cannot be isolated at physiological temperature, but

\footnotetext{
Abbreviations used: DRM, detergent resistant membrane; DTT, dithiothreitol; EM, electron microscope; GPI, glycosylphosphatidylinositol; ISB, intracellular solubilisation buffer; $\mathrm{L}_{\mathrm{d}}$, liquid disordered; $\mathrm{L}_{\mathrm{o}}$, liquid ordered; $\mathrm{MBCD}$, methyl-B-cyclodextrin; SB, standard solubilization buffer; PrP, prion protein; WGA, wheat germ agglutinin.

${ }^{1}$ To whom correspondence should be addressed: roger.morris@kcl.ac.uk

Dr Roger Morris, King's College London, Wolfson Centre for Age Related Disease, Hodgkin Bldg, Guy's Campus,

London SE1 1UL UK. Tel +44 $2078486801 \quad$ Fax +44 2078486816
} 
only at $4^{\circ} \mathrm{C}[4,6]$. Many membrane lipids that at $37^{\circ} \mathrm{C}$ are in a fluid $\mathrm{L}_{\mathrm{d}}$ phase, on chilling to $4^{\circ} \mathrm{C}$ form an ordered, detergent-resistant gel phase. DRMs isolated at $4^{\circ} \mathrm{C}$ must include lipids that are in $\mathrm{L}_{\mathrm{d}}$ phase at $37^{\circ} \mathrm{C}$ $[4,5]$. If exclusion of detergent from an $\mathrm{L}_{\mathrm{o}}$ phase is the criterion for selection of DRMs, it is not easy to explain why 'raft' membrane in an $\mathrm{L}_{\mathrm{o}}$ phase cannot be isolated at $37^{\circ} \mathrm{C}$ on the basis of detergent insolubility.

In addition, DRMs made with the benchmark detergent Triton X-100 have been shown to contain proteins from totally different cells [7] and to have scrambled the asymmetry of the surface membrane [8], results pointing to merger during solubilization of membrane fragments that are unrelated on the cell surface. This possibly results from the tendency of Triton X-100 to selectively deplete inner leaflet lipids from DRMs [911], which would destabilise and presumably merge membrane patches into larger vesicles. This effect, however, is not found with all non-ionic detergents. In particular, Brij 96 used under similar conditions does not selectively deplete inner membrane lipids $[11,12]$, nor fuse fragments from different membranes into mixed DRMs [7], nor scramble membrane symmetry [8].

However, the inner leaflet of the plasma membrane differs in lipid composition and phase characteristics from the outer leaflet, making it more vulnerable to disruption during membrane solubilization. Unlike the outer leaflet, whose major components (phosphatidylcholine and sphingomyelin) each form stable leaflets, the major inner leaflet lipid, PE, cannot by itself form a lamellar phase unless mixed with negatively charged PS $^{-}$whose large hydrated headgroup complements the small headgroup of PE to seal the membrane-water interface [13-15]. This balanced mosaic of intracellular lipids is dependent upon exclusion of $\mathrm{Ca}^{2+}$, maintained extracellularly at $1.2 \mathrm{mM}$ but held within the cytoplasm at sub- $\mu \mathrm{M}$ basal levels. Sustained influx of $\mu \mathrm{M} \mathrm{Ca}^{2+}$ into the cell leads to separation of PS into $\mathrm{Ca}^{2+}$-chelated PS domains, leaving PE to either fuse with nearby membrane, or delaminate to form non-bilayer reverse hexagonal phases [16-19]. Cholesterol condensed with saturated PE and $\mathrm{PS}^{-}$in the inner leaflet [20] sensitizes further the $\mathrm{Ca}^{2+}$ chelation of $\mathrm{PS}^{-}$and separation of PE into an hexagonal phase [21].

Uncontrolled high levels of $\mathrm{Ca}^{2+}$ will access the cytofacial leaflet as the plasma membrane is disrupted by homogenization and the major intracellular $\mathrm{Ca}^{2+}$ stores (ER, mitochondria and lysosomes) are lysed by detergent; if unchecked, this $\mathrm{Ca}^{2+}$ would destabilize PE at its interface with water, the region Triton X-100, with its short, bulky hydrophobic chain will particularly perturb in contrast to the long, monolayer-spanning hydrophobic chain of Brij 96 (Supplementary Figure 1). Addition of $\mathrm{Ca}^{2+}$ chelators such as EGTA to buffers should limit the destabilization of the inner leaflet as the cell is disrupted, but it has not prevented the selective depletion of inner leaflet lipids nor scrambling of the asymmetry of membrane proteins by Triton $\mathrm{X} 100[8,11]$. In order to maintain full membrane-dependent function in isolated cytosolic organelles, such as translocation of protein in RER microsomes [22], it is necessary to not only remove $\mathrm{Ca}^{2+}$, but also provide $\mathrm{Mg}^{2+}$ and $\mathrm{K}^{+}$in a reducing buffer, where the effect of $\mathrm{Mg}^{2+}$ in promoting lipid order [23] may be particularly relevant.

We have therefore investigated whether solubilization using buffers that chelate $\mathrm{Ca}^{2+}$, or further mimic the intracellular ionic environment, stabilize membrane domains sufficiently to allow subsets to be isolated at $37^{\circ} \mathrm{C}$ as DRMs. We show this in detail for Brij 96, with which we have extensive experience in DRM isolation at $4^{\circ} \mathrm{C}[7,24,25]$. Experiments with Triton $\mathrm{X}-100$ are included to show that cytoplasmic cations affect membrane solubilization by this detergent also. Brij 98 (with a similar $\mathrm{C}_{18} \mathrm{H}_{35}$ alkyl chain to Brij 96 but with $\sim 20$ polyoxyethylene head groups), that alone of non-ionic detergents can be used to isolate DRMs at $37^{\circ} \mathrm{C}$ without using intracellular cations [26,27], is also briefly examined with these buffers.

\section{EXPERIMENTAL}

\section{Animals and reagents}

Wistar rats aged 4 weeks were killed by $\mathrm{CO}_{2}$ inhalation, their brains immediately removed and homogenized. PrP, Thy-1 and LRP1 were detected by antibodies as described [28]; rabbit antibodies to Fyn (sc-434) and Src (sc-56890) were from Santa Cruz; mouse anti-actin (clone 4), anti-tubulin (clone DM1A) and rabbit antiflotillin-1 (E446) were from Chemicon. Fab antibody fragments from Ox7 anti-Thy-1 and 2S anti-PrP antibodies, and wheat germ agglutinin (WGA), were directly coupled to 5 and $10 \mathrm{~nm}$ gold (British BioCell Ltd) as described [25]. Laboratory chemicals were analytical grade from standard suppliers. 


\section{Membrane preparation and solubilization}

Standard solubilization buffer (SB) was $250 \mathrm{mM}$ sucrose, $10 \mathrm{mM}$ Tris-HCl pH 7.4 and $1 \mathrm{mM}$ EGTA with protease inhibitor mini-tablets (Roche) and $1 \mathrm{mM}$ PMSF added before use. Intracellular solubilization buffer (ISB) was $200 \mathrm{mM}$ sucrose, $10 \mathrm{mM}$ Hepes- $\mathrm{KOH}$ (pH 7.6), $50 \mathrm{mM} \mathrm{KOCOCH}_{3}, 1 \mathrm{mM} \mathrm{Mg}\left(\mathrm{OCOCH}_{3}\right)_{2}$ and 1 mM EGTA with protease inhibitor mini-tablets, $1 \mathrm{mM}$ PMSF and $1 \mathrm{mM}$ DTT (dithiothreitol) added before use. Homogenization ( $5 \mathrm{ml}$ buffer per brain) was with a Dounce homogenizer with the tight-fitting pestle on ice. When particulate membrane fragments were no longer observed ( 30 strokes), nuclei were pelleted at $5,000 \mathrm{~g}$ for 5 mins (Beckman Coulter Avanti J25 centrifuge, JA18.1 rotor) then membranes at $30,000 \times \mathrm{g}_{\mathrm{av}}$ for $40 \mathrm{~min}$ (Beckman Optima Ultracentrifuge, TLA120.2 rotor). The membrane pellet was resuspended in half the original volume, repelleted as before, then the resuspended pellet twice depleted of myelin by ultracentrifugation through a $0.5-2.0 \mathrm{M}$ sucrose gradient, with myelin (fractions lighter than $0.8 \mathrm{M}$ sucrose) discarded while Thy- 1 and $\operatorname{PrP}$ were recovered in membrane fractions from 1.0 to $1.5 \mathrm{M}$ sucrose. Protein concentration was determined (on aliquots solubilized in 0.1\% SDS) by the Bradford method (BioRad Detergent Compatible Protein Assay Reagents Package); final concentrations were adjusted for solubilization to $10 \mathrm{mg} / \mathrm{ml}$ of membrane protein. Detergent solutions at double strength were mixed with equal volume of membrane homogenate. Solubilization was at $4^{\circ} \mathrm{C}$ for $15 \mathrm{~min}$, or membranes were preequilibrated at $37^{\circ} \mathrm{C}$ for $5 \mathrm{~min}$ and detergent added for another $5 \mathrm{~min}$. Where indicated, membranes in ISB were pre-incubated with or without $5 \mathrm{mM} \mathrm{M \beta CD}$ (methyl- $\beta$-cyclodextrin) for $30 \mathrm{~min}$ at $37^{\circ} \mathrm{C}$, then detergent added. Solubilized membranes were diluted $1: 1$ with $80 \%$ sucrose at $4^{\circ} \mathrm{C}$ and loaded at the bottom of the centrifuge tubes. Gradients of 5 30\% sucrose prepared in the relevant buffer with detergent (1\% Triton X$100,0.5 \%$ Brij 96) were layered on top to a total volume of $12 \mathrm{ml}$ and centrifuged to equilibrium $(170,000$ $\times \mathrm{g}_{\mathrm{av}}$ for $18 \mathrm{hr}$ at $4^{\circ} \mathrm{C}^{\prime}$; SW40Ti rotor in a Beckman XL90 ultracentrifuge). Serial $1 \mathrm{ml}$ aliquots were aspirated from the top of gradients. Pellets were taken up in $1 \mathrm{ml}$ and resuspended by sonication $(30 \mathrm{kHz}, 1 \mathrm{~min}$; Ultrasonic Homogenizer 4710, Cole-Parmer Instrument, USA).

Sensory neurons, cultured for 5-7 days from the dorsal root ganglia of 4-6 week old rats [28] were harvested with a teflon scraper and collected at $800 \mathrm{~g}$ for $5 \mathrm{~min}$. Cultured neuroblastoma-derived N2a cells were similarly harvested. Both cell pellets were resuspended in ISB and fragmented in a $45 \mathrm{ml}$ nitrogen bomb (PS152BAR, Parr Instrument, USA) at 1200 to 1300 psi after equilibrating for $5 \mathrm{~min}$ at $4^{\circ} \mathrm{C}$. Nuclei were pelleted as above, DNAse (Promega) added at $10 \mathrm{unit} / \mathrm{ml}$ to postnuclear supernatant and protein concentration determined. Sensory neuronal membranes were adjusted to $1 \mathrm{mg}$ protein/ml to which an equal volume of $0.1 \%$ Brij 96 in ISB was added; N2a membranes were adjusted to $10 \mathrm{mg}$ protein $/ \mathrm{ml}$ to which 1.0 $0.1 \%$ Brij 96 was added. Sucrose gradients $(5 \mathrm{ml}$ total $)$ were centrifuged to equilibrium $\left(300,000 \times \mathrm{g}_{\mathrm{av}}\right.$ for 18 hr at $4^{\circ} \mathrm{C}$; TLS-55 rotor, Beckman Optima ultracentrifuge).

\section{Immunoprecipitation (IP)}

Purified IgG (Ox7 for Thy-1, 2S for PrP), coupled at $1 \mathrm{mg} / \mathrm{ml}$ to Dynabeads M-280 Tosyl activated, blocked with ethanolamine according to manufacturers instructions (Dynal Biotech), was incubated with gradient fractions at $4^{\circ} \mathrm{C}$ with gentle rotation from $1 \mathrm{hr}$ to overnight. Beads retained with a magnet were washed with $1 \mathrm{ml} \mathrm{SB}$ plus $0.1 \%$ Brij 96 , then twice with $0.01 \%$ Brij 96 before bound protein, recovered by boiling for 5 min in non-reducing sample buffer [29] was electrophoresed and immunoblotted.

\section{EM (electron microscopy)}

For evaluation of glycoprotein asymmetry, DRMs were fixed by $1 \%$ paraformaldehyde and $0.1 \%$ glutaraldehyde in their gradient buffer at $4^{\circ} \mathrm{C}$ overnight, then spun down by centrifugation at $30,000 \times \mathrm{g}$ for 1 hr (Beckman Coulter Avanti J25, JA18.1 rotor). The pellet was resuspended in $5 \mu 1$ 10\% gelatine that was allowed to set by placing the tube on ice for 30 mins. Small pieces of the pellet were cryo protected by exposure to $2.3 \mathrm{M}$ sucrose overnight at $4^{\circ} \mathrm{C}$, placed onto a pin and cryofixed by plunging into liquid nitrogen. Sections ( $80 \mathrm{~nm}$ thick) were cut at $-80^{\circ} \mathrm{C}$ using an RMC cryo-ultramicrotome, and transferred to Pioloform coated Ni EM grids where they were washed with PBS then remaining aldehyde groups blocked with $50 \mathrm{mM}$ glycine in PBS pH 7.2. Sections were incubated with $0.1 \mu \mathrm{g} \mathrm{WGA} / \mathrm{ml}$ in PBS for $4 \mathrm{hr}$, washed in PBS then fixed in 2\% glutaraldehyde in PBS for 5 min. Grids were contrasted in a mixture of 1 part $3 \%$ uranyl acetate in 9 parts 2\% methylcellulose for 10 min and viewed in a Technai 12 transmission EM. 
Immediately before use, immunogold preparations were precleared by centrifugation for $1 \mathrm{hr}$ to remove any aggregates that may have formed: $5 \mathrm{~nm}$ gold was spun at $25,000 \mathrm{~g}$ (the force used to pellet $10 \mathrm{~nm}$ gold) and $10 \mathrm{~nm}$ gold was spun at $15,000 \mathrm{~g}$ (the force used to pellet $15 \mathrm{~nm}$ gold; Beckman Coulter Avanti J25 centrifuge, JA18.1 rotor). For Thy-1 and PrP immunolabelling, DRMs were incubated with Fab antibody fragments of OX7/2S directly coupled to $5 / 10 \mathrm{~nm}$ gold respectively $(0.1 \mu \mathrm{g}$ protein $/ \mathrm{ml}$ for each antibody) at $37^{\circ} \mathrm{C}$ for 0.5 hour. In the control experiment, R194 anti-mouse Thy-1.2 and 3F4 anti-human PrP antibodies, directly coupled to gold as before, were used. Unbound gold was removed by centrifugation $(14,000 \mathrm{~g}, 5$ min) through $40 \%$ sucrose; labelled DRMs at the interface were pelleted by centrifugation $(14,000 \mathrm{~g}, 2 \mathrm{~min})$ and the pellet fixed overnight in $2 \%$ paraformaldehyde $/ 0.1 \%$ glutaraldehyde for $1 \mathrm{hr}$. Samples were postfixed with $\mathrm{OsO}_{4}(\mathrm{pH} 7.3)$ at $4^{\circ} \mathrm{C}$ for $1.5 \mathrm{hr}$, dehydrated through ascending ethanol solutions into TAAB epoxy resin (TAAB Laboratory Equipment Ltd, Aldermaston UK). The resin blocks were cut with diamond blades on a Leica Ultra-Cut microtome to 80 120 nm ultra-thin sections and picked up on to 150 mesh Guilder Grids with a support film of Pioloform. Grids, stained with uranyl acetate ( $25 \%$ solution in absolute methanol) and lead citrate (4.4\% (w/v), in $\mathrm{CO}_{2}$-free $\mathrm{H}_{2} \mathrm{O}$ ), were viewed under TEM (Hitachi H7600, Japan).

The 5 and $10 \mathrm{~nm}$ gold particles were initially confirmed to be of that diameter using Gatan on-screen measuring software, and thereafter identified by eye using the 4 fold difference in their cross-sectional areas, and difference in contrast, as a guide. Quantitation was done manually on high power prints by overlaying a transparency on which were printed bars of 20 and $150 \mathrm{~nm}$; particles present on different membrane fragments were not counted as being adjacent on the membrane.

\section{RESULTS}

DRMs were isolated from myelin-depleted brain membranes by detergent solubilization followed by ultracentrifugation to equilibrium in a sucrose density gradient $[7,24]$ using either Solubilization Buffer (SB) containing $1 \mathrm{mM}$ EGTA to chelate $\mathrm{Ca}^{2+}$, or Intracellular Solubilization Buffer (ISB) to reproduce aspects of the intracellular ionic environment $\left(\mathrm{Mg}^{2+}, \mathrm{K}^{+}\right.$and a reductive agent) during homogenization and solubilization. Preliminary experiments using dynamic light scattering found very little difference in the hydrodynamic size of micelles formed by either Triton X-100 or Brij 96 in the two buffers (Supplementary Figure 2), in keeping with the low susceptibility of non-ionic surfactants to buffer composition [30].

\section{Effect of buffer composition on isolation of 'raft' proteins as DRMs at $4^{\circ} \mathrm{C}$}

As a preliminary control, the migration of membrane proteins in the density gradient prior to adding detergents was determined (Figure 1A). Both GPI-anchored Thy-1 and PrP remained within the loading fractions (11 and 12) of $40 \%$ sucrose at the bottom of the gradient, with some PrP also pelleting at the bottom of the gradient. Actin, the structural protein of the cortical cytoskeleton that is anchored via adaptor proteins to transmembrane protein complexes, was also recovered in the loading fractions, although a small fraction of actin and PrP rose higher in the gradient, suggesting their association with low density, lipid-rich membrane fragments. Recovery of proteins in the loading fractions after solubilization is often interpreted as their being fully solubilized; to test whether this was the case here, the $40 \%$ sucrose fractions were diluted to $8 \%$ sucrose and centrifuged at $45,000 \mathrm{~g}$ for $3 \mathrm{hr}$ (Figure 1A, right panel). All three proteins were recovered in the pellet and so were in membranes rather than fully solubilized.

Brain membranes were solubilized for $15 \mathrm{~min}$ at $4^{\circ} \mathrm{C}$, in both SB and ISB, in Triton X-100 (Figure 1B) and Brij 96 (Figure 1C), at concentrations (1\% and $0.5 \%$ detergent respectively with $5 \mathrm{mg} / \mathrm{ml}$ membrane protein) found previously to give optimal release of PrP and Thy-1 DRMs [7]. The distribution of Thy-1 and $\operatorname{PrP}$ on the gradient after solubilization in SB was very similar to that previously described [7], with the proteins moving to lighter density in Brij 96 compared to Triton X-100. Both detergents in SB caused a major part of actin to pellet at the bottom of the gradient, with the rest primarily in the loading fractions.

In ISB, however, the major fraction of Thy-1 and PrP remained either in the loading fractions, or (Thy-1 in Brij 96) in fractions 7-10 of intermediate density. Relatively little of these proteins floated at the low density found with solubilization in SB. In addition, in the presence of ISB, some actin floated further up the gradient in fractions 2-7 that would normally contain DRMs. When the loading fractions $(11+12)$ recovered 
from gradients on which membranes solubilized in either detergent in ISB were diluted to $8 \%$ sucrose and recentrifuged, virtually all Thy- 1 and PrP was pelleted, indicating they remained in unsolubilized membrane (Figure 1B, C, right panels). This centrifugation test to determine whether protein was membrane-associated or fully solubilized was routinely applied hereafter to the loading fractions.

\section{Solubilization at $37^{\circ} \mathrm{C}$}

Since ISB protected membranes against solubilization at $4^{\circ} \mathrm{C}$, the effect of the buffer upon solubilization at $37^{\circ} \mathrm{C}$ was investigated. Figure 2 shows the effect of ISB compared to SB upon solubilization of brain membranes for 5 min at $37^{\circ} \mathrm{C}$ in Brij 96 and Triton X-100. Brij 98 in both buffers was also tested, using 15 min solubilisation at $37^{\circ} \mathrm{C}$ as described by Drevot et al [26].

Following solubilisation in Brij 96 or Triton X-100, a substantial portion of the GPI-anchored proteins, and the intracellular 'raft' protein flotillin-1 (not shown for Triton X-100), floated at the top of the gradient (fractions 2-4) irrespective of whether SB or ISB was used. Upon dilution to 5\% sucrose, Thy-1 and PrP in these light fractions could all be pelleted by centrifugation $(45,000 \mathrm{~g}, 3 \mathrm{hr})$, confirming their membrane nature (not shown; see Figures 6,7 below). LRP1, the transmembrane endocytic partner for PrP on neurons [28] remained within the loading fractions. Pre-treatment of the membranes with the cholesterol chelator, methylB-cyclodextrin (MBCD), depleted this low density fraction as expected for cholesterol-dependent DRMs [6]. These results together argue that it is possible to isolate DRMs from neuronal membranes by solubilization at $37^{\circ} \mathrm{C}$ using either SB or ISB.

Solubilization in ISB differed from that using SB in delivering Thy-1 and PrP DRMs in a smaller number of fractions; in addition, a small proportion of the intracellular diacylated kinase Fyn, and even some of the monoacylated kinase Src, floated within the DRM fraction when ISB but not SB was used (Figure 2A). A small proportion of the cytoskeletal proteins actin and tubulin also floated at low density in ISB but not SB.

Similar results to those shown in Figure 2 were obtained with shorter (30 \& 60 second) solubilization times although 5 min proved more reproducible in the proportion of Thy- 1 and PrP released to float at low density (not shown). With longer solubilization (30-60 min) at $37^{\circ} \mathrm{C}$, sphingomyelinase degradation of raft sphingomyelin becomes evident [12].

Brij 98 in SB showed a pattern of solubilization similar to that seen using ISB with Triton X-100 or Brij 96, in that much of the GPI-anchored proteins, and some Fyn and Src, floated at low density. ISB, however, appeared to stabilize the membrane too strongly to allow effective solubilization by Brij 98, since most of the GPI-anchored proteins and cytoplasmic kinases remained in the loading fractions (Figure 1C), from which they could be pelleted by centrifugation (not shown) and so were membrane associated.

\section{Stability of DRMs at $37^{\circ} \mathrm{C}$ and above}

Membranes solubilized as above were at $37^{\circ} \mathrm{C}$ for just $10 \mathrm{~min}: 5 \mathrm{~min}$ to pre-equilibrate, then 5 min more with detergent. Subsequent gradient preparation and $18 \mathrm{hr}$ ultracentrifugation was at $4^{\circ} \mathrm{C}$, during which detergent was also present in the gradient. To determine whether DRMs isolated at $37^{\circ} \mathrm{C}$ remain stable at this temperature, samples processed at $37^{\circ} \mathrm{C}$ for gradient formation and ultracentrifugation were compared with those centrifuged in a gradient at $4^{\circ} \mathrm{C}$. As shown in Figure 3 for Triton X-100, both Thy- 1 and $\operatorname{PrP}$ on the external surface, and flotillin-1 on the inner surface, floated at 2-3 fractions lighter density when ultracentrifuged at $37^{\circ} \mathrm{C}$. This indicates a higher lipid to protein ratio at the higher temperature, and longterm stability of the DRMs at $37^{\circ} \mathrm{C}$.

Since $\mathrm{L}_{\mathrm{o}}$ domains can be stable up to $\sim 50-60^{\circ} \mathrm{C}[31,32]$ it should be possible to obtain DRMs after solubilization at temperatures higher than $37^{\circ} \mathrm{C}$. This was explored with solubilization for 5 min using Triton X-100 in ISB at higher temperatures (followed by ultracentrifugation at $4^{\circ} \mathrm{C}$ ). DRMs of Thy- 1 and PrP remained resistant to solubilization at temperatures up to $50-55^{\circ} \mathrm{C}$ (Figure 4 ).

\section{Separate immunoisolation of PrP and Thy-1 DRMs in ISB/Brij 96 at $37^{\circ} \mathrm{C}$}

Since Thy- 1 and PrP DRMs could be immunopurified largely as separate DRMs after solubilization using Brij 96 at $4^{\circ} \mathrm{C}$ [24], immunoaffinity separation of DRMs was undertaken after solubilization at $37^{\circ} \mathrm{C}$. Since Thy-1 is the more abundant protein on the neuronal surface [7], PrP was first immunoisolated then Thy-1 was purified from the PrP-depleted fraction. Each protein was recovered almost entirely free of the other 
(Figure 5). Actin was co-eluted with Thy-1 DRMs but not PrP DRMs, but not when the DRMs were fully solubilized, suggesting that actin does not bind directly to Thy-1 but to some other component of its DRMs.

\section{Preservation of asymmetry of glycoproteins in DRMs isolated at $37^{\circ} \mathrm{C}$}

DRMs isolated from fractions 3+4 of sucrose gradients, after solubilization in Brij 96 in ISB, were fixed, snap-frozen, cryo-sectioned and labelled with WGA coupled to $5 \mathrm{~nm}$ gold, to identify the extracellular glycan chains of glycoproteins that are present only extracellularly [33]. This method allows equal access of the lectin to both sides of the DRM membrane, so that any scrambling of the natural asymmetry of the plasma membrane should be evident as scrambling of WGA-gold labelling on both sides of the DRM membrane. Typical results for Brij 96 DRMs are shown in Figure 6. Interpretation of results is complicated because the cryo-sections are $\sim 80 \mathrm{~nm}$ thick, whereas many of the labelled DRMs are smaller so that their membrane is often seen en face as it curves within the plane of the section (e.g. Figure 6, top left). However, whenever a clear cross-section of membrane was seen, the WGA label was always on the external surface only, indicating that DRMs preserve an outside-out orientation of membrane, and do not randomly scramble the in vivo asymmetry of the plasma membrane.

\section{Morphology of individual Thy-1 and PrP DRMs isolated at $37^{\circ} \mathrm{C}$}

The ultrastructure of individual Brij 96/ISB DRMs taken from gradient fractions 3+4 was examined in the EM by immunolabelling DRMs at $37^{\circ} \mathrm{C}$ with anti-PrP Fab on $5 \mathrm{~nm}$ gold, and anti-Thy-1 Fab on $10 \mathrm{~nm}$ gold (Figure 7). The overall vesicle population varied considerably in size and shape, with $\sim 30 \%$ of the vesicles immunolabelled for either Thy-1 or PrP. En face and glancing side views of membranes predominate.

Virtually all PrP label occurred in large clusters, often in linear arrays (e.g. Figure 7C-F) as found on the surface of cultured neurons $[7,24,25]$. At the magnification reproduced here, overlapping $5 \mathrm{~nm}$ grains within a cluster could be mistaken for $10 \mathrm{~nm}$ label (e.g. Figure 7C, E), although overlapping particles lack the symmetry and contrast of single $10 \mathrm{~nm}$ gold particles. With overlapping label, individual grains were resolved at high power under the microscope, and their size and number noted for quantitation. PrP clusters only occasionally had Thy-1 label near them (e.g. Figure 7F; applying the same criterion as [24] only 3.9 $\pm 2.0 \%$ (mean \pm s.e.m.) of PrP label was within $20 \mathrm{~nm}$ of Thy-1). However, a single DRM that contained a large PrP cluster could also contain a relatively distant label for Thy-1 (e.g. Figure 7C,G).

Thy-1 label most frequently occurred at low density upon thin tubular structures (Figure 7I-K) that were possibly derived from axons, although larger clusters were also found (Figure $7 \mathrm{H}, \mathrm{L}$ ). Most Thy-1 was not associated with PrP immunolabelling $(3.2 \pm 1,4 \%$ Thy-1 label was within $20 \mathrm{~nm}$ of PrP label, and even extending the range, only $13.1 \pm 4.5 \%$ of Thy-1 label was within $150 \mathrm{~nm}$ of labelled PrP).

The striking feature of these images, however, is that the labelled GPI-anchored proteins occupy only a small fraction of the DRM surface; the major part of DRMs isolated under these conditions was not occupied by our 'marker' proteins. This was also found with DRMs isolated in Brij 96 at $4^{\circ} \mathrm{C}$ [7].

\section{Isolation of DRMs at $37^{\circ} \mathrm{C}$ from primary cultured adult sensory neurons}

To test whether DRMs could be isolated at $37^{\circ} \mathrm{C}$ from cultured cells, sensory neurons were chosen as they can uniquely be cultured from adult animals [34]. Neurons were fragmented by $\mathrm{N}_{2}$ cavitation, their membranes collected by centrifugation and run on a sucrose density gradient where colloidal gold staining showed their proteins were recovered in the loading fractions and pellet, and not in the low density fractions (Supplementary Figure 3A). The small amounts of material limited the membrane protein concentration to $0.5 \mathrm{mg} / \mathrm{ml}$, so Brij 96 was proportionately diluted to $0.05 \%$ for solubilization for $5 \mathrm{~min}$ at $37^{\circ} \mathrm{C}$, releasing membrane protein to float at low density (Supplementary Figure 3B). Virtually all Thy-1 floated as low density DRMs (fractions 1-3; Figure 8), whereas only $\sim 10 \%$ of PrP floated as somewhat heavier DRMs (fractions 3-5), the majority remaining in the loading fraction (where it was fully solubilized by the criterion of not being pelleted by ultracentrifugation; not shown). This difference between the two GPI-anchored proteins matches the almost exclusive location of Thy-1 on the surface, and of $90 \%$ of PrP in intracellular, membranes on these neurons $[25,28]$. Flotillin-1 behaved very similarly to PrP, the majority being fully solubilized but some floated in fractions 3-5. The intracellular diacylated kinase Fyn was largely recovered in the pellet (fraction 12), probably as part of larger protein complexes; but a proportion was recovered in the Thy-1-rich fraction 1. Two 'non-raft' proteins, monoacylated Src and transmembrane LRP1, remained 
entirely (LRP1) or largely (Src) in the loading fractions with no trace in DRM fractions 1-5. Actin was primarily in the pellet, but a very small proportion floated as high as fraction 1.

\section{Isolation of DRMs at $37^{\circ} \mathrm{C}$ from N2a Cells}

N2a cells were similarly fragmented by $\mathrm{N}_{2}$ cavitation and solubilized with Brij 96 in ISB at $4^{\circ} \mathrm{C}$ and $37^{\circ} \mathrm{C}$ at the same protein concentration $(5 \mathrm{mg} / \mathrm{ml})$ used with brain membranes. It was found that $0.5 \%$ Brij 96 solubilized most of the $\operatorname{PrP}$ at $37^{\circ} \mathrm{C}$ (not shown), and lowering the detergent concentration to $0.05 \%$ was required to obtain PrP and flotillin-1 in low density fractions; no actin was recovered in DRM fractions (Figure 9). Thy-1 was not assessed as N2a cells do not express it.

The distinctive difference between solubilization at 4 and $37^{\circ} \mathrm{C}$ was in the size of the DRMs obtained, which were smaller and more homogeneous at $37^{\circ} \mathrm{C}$, irrespective of whether ISB or SB was used (Supplementary Table 1).

\section{DISCUSSION}

This paper examines the hypothesis that ionic stabilization of the lamellar phase of inner leaflet lipids enables $\mathrm{L}_{\mathrm{o}}$ nanodomains on the cell surface to resist detergent solubilization at physiological temperature. Experimentally convenient immunoassays of 'raft' proteins have been used to explore relevant variables; lipid and structural analyses will be reported elsewhere (Chen et al, in preparation; [12]).

Demyelinated membranes from adult rat brain have been used as starting material, providing fully differentiated plasma membranes, albeit of mixed cellular origin (neurons, glia and vasculature). Two GPIanchored 'raft' proteins, Thy- 1 and PrP, are expressed only on neurons in normal adult brain [35, 36], and occupy topographically, biochemically and functionally different nanodomains on the neuronal surface [7, $24,25,37]$. Their behaviour during solubilization monitors the detergent resistance of distinct sub-domains of the surface of mature neurons. To monitor the integrity of the inner leaflet, flotillin, that inserts into this leaflet via a polypeptide loop, and Fyn, that inserts via two acyl chains, have been used [38]. Src, similar to Fyn but with only one acyl chain inserting into the lipid bilayer, is found at $4^{\circ} \mathrm{C}$ not to associate with DRMs [38]. The cytoskeletal structural proteins actin and tubulin were included, since although the vast majority of these proteins are in cytoplasmic and cytoskeletal pools, a very minor proportion contacts and organizes the topography of transmembrane proteins. Finally, LRP1 has been used as an example of a transmembrane protein not normally found within rafts [28].

DRMs could be isolated from brain membranes and cultured adult sensory neurons at $37^{\circ} \mathrm{C}$ using the same detergent:protein ratio; however, with the N2a cell line, this ratio had to be lowered 10-fold. The source of the higher detergent resistance of the adult neuronal membrane is unknown, but correlates with the high resistance (compared to cell lines) to transfection of DNA vectors into primary cells in general, and into adult neurons in particular [39]. These differences in permeability of surface membranes, whether to detergent solubilization or large DNA complexes, means that no single protocol for DRM isolation applies to all cell types. The basic approach needs to be fine tuned to match the membranes studied.

Surprisingly, both Thy -1 and PrP floated within low density membrane fragments after solubilization at $37^{\circ} \mathrm{C}$ in either Triton X-100 or Brij 96, irrespective of the buffer (SB or ISB) used. However, incorporation of cytofacial leaflet proteins in DRMs was improved using ISB, so ISB/Brij 96 DRMs were characterised both biochemically and ultrastructurally.

The association of proteins with ISB/Brij 96 DRMs isolated at $37^{\circ} \mathrm{C}$ agrees with known differences in their biochemistry. Functionally, Thy-1 inhibits signalling of Src-family kinases [40], of which Fyn is the main diacylated member in neurons and floated in the same light DRM fractions as Thy- 1 . The actual proportion of total Fyn in the DRM fraction was low, with most in the pellet or solubilized fractions. We find a similar low proportion of Fyn in brain DRMs isolated at $4^{\circ} \mathrm{C}$ (not shown), presumably because in neurons most Fyn associates with adhesion and postsynaptic density fractions that are not within $\mathrm{L}_{\mathrm{o}}$ phase membrane. Neurons differ from the immortalized cell lines typically used for raft studies in being post-mitotic and nontransformed, primary cultured cells, which may account for their different compartmentalization of Fyn. Actin is involved in raft signalling (e.g. [41, 42]), which may explain its selective association with Thy-1 DRMs. With cultured sensory neurons, PrP occurred in denser DRMs (peak fractions 4/5) than Thy-1 (peak 
fractions 1-3), confirming independently of immunoaffinity isolation or immunolabelling, the separate identity of PrP and Thy-1 nanodomains on these neurons. The DRM component of flotillin-1 peaked with PrP, in keeping with its involvement in PrP signalling [43].

One notable benefit of solubilization at $37^{\circ} \mathrm{C}$ was the almost complete immunoseparation of PrP from Thy-1 DRMs compared to the presence of $20 \%$ of PrP in Thy-1 DRMs at $4^{\circ} \mathrm{C}$ [24]. This separation, seen also at the level of immunogold labelled vesicles, argues that merger of neuronal surface nanodomains in detergent has not occurred since it would inevitably merge Thy-1 and PrP domains that are often within $\mu \mathrm{m}$ of each other on the neuronal surface [7, 24, 25]. Further, the distinctive clustering of PrP on the neuronal surface $[7,24,25]$ is retained in isolated DRMs. WGA labelling of cryo-sections of DRMs showed labelling only on their outer surface, again indicating that arbitrary merger of rafts had not occurred. Were raft membrane to curl arbitrarily upon solubilization, glycan labelling would be found equally on the inner or outer surface of individual vesicles. Label was only found on the outer surface, possibly because the Brij 96 causes lipid rafts to vesiculate from the surface, similar to Triton X-100-induced budding of Lo domains from giant unilamellar vesicles [44]. However, Triton X-100 scrambles membrane orientation in individual DRMs isolated from cells [8], arguing that solubilization of cell membranes is more complex than that of pure lipid bilayers. A factor that could confer intrinsic convex pressure in raft membrane is the extraordinarily large glycoprotein headgroup on the GPI lipid, which should act like other disproportionately large lipid headgroups to impose convex curvature on raft membrane $[38,45]$.

The larger clusters of 20-40 grains of monovalent immunogold label for Thy-1 and PrP that we find on isolated DRMs and on the neuronal surface $[24,25]$ are contrary to findings that GPI-anchored proteins are not confined to recognisable domains until they are cross-linked by ligand [46-48] or multivalent antibody [49]. The GPI-anchored proteins in these fluorescence-based studies do not include Thy-1 or PrP. Fluorescence correlation spectroscopy shows Thy-1 to be confined to 40-120 nm domains on living cells [50, 51] similar to those seen in the EM. We therefore suggest that the expectation that all GPI-anchored proteins are not clustered until cross-linked reflects the range of molecules and cell types examined, and does not apply to neuronal rafts of Thy-1 and PrP.

Immunolabelled PrP and Thy-1 occupy an unexpectedly small part of their DRMs, suggesting that both proteins are clustered due to properties additional to their partitioning into $\mathrm{L}_{\mathrm{o}}$ domains, and occupy only a small proportion of their rafts. Studies show that the $L_{o}$ phase can be the major lipid phase on some cell surfaces (e.g. [52, 53]) whereas our fluorescent and EM immunolabelling indicate that Thy-1 and PrP occupy at most a few $\%$ of the neuronal surface $[7,24,25]$. Although the mechanism is currently unclear, clustering of PrP and Thy- 1 on the neuronal surface into sub-regions of larger, $\mathrm{L}_{\mathrm{o}}$ phase lipid domains is possible.

Overall, the use of a buffer that reproduces aspects of the intracellular environment during solubilization enables the isolation of DRMs at $37^{\circ} \mathrm{C}$ that have properties compatible with their being isolated lipid 'rafts'. It is now possible to identify their composition and determine whether these components associate at the surface membrane of the living cell. Our results further indicate the need to examine the topographical relationship on neurons between raft proteins and lipids.

This work was aided by a grant from the Human Frontier Science Program (RGP0016/2005C) to PJQ. XC was supported by a King's College post-graduate studentship and an ORS award.

\section{REFERENCES}

1 Simons, K. and Ikonen, E. (1997) Functional rafts in cell membranes. Nature 387, 569-572

2 Brown, D. A. and Rose, J. K. (1992) Sorting of GPI-anchored proteins to glycolipid-enriched membrane subdomains during transport to the apical cell surface. Cell 68, 533-544

3 Hooper, N. M. and Bashir, A. (1991) Glycosyl-phosphatidylinositol-anchored membrane proteins can be distinguished from transmembrane polypeptide-anchored proteins by differential solubilization and temperature-induced phase separation in Triton X-114. Biochem. J. 280, 745-751

4 London, E. and Brown, D. A. (2000) Insolubility of lipids in triton X-100: physical origin and relationship to sphingolipid/cholesterol membrane domains (rafts). Biochim. Biophys. Acta 1508, 182-195

5 Lichtenberg, D., Goni, F. M. and Heerklotz, H. (2005) Detergent-resistant membranes should not be identified with membrane rafts. Trends Biochem. Sci. 30, 430-436 
6 Lingwood, D. and Simons, K. (2007) Detergent resistance as a tool in membrane research. Nat. Protoc. 2, 2159-2165

7 Madore, N., Smith, K. L., Graham, C. H., Jen, A., Brady, K., Hall, S. and Morris, R. (1999) Functionally different GPI proteins are organised in different domains on the neuronal surface. EMBO J. 18, 6917-6926

8 Radeva, G. and Sharom, F. J. (2004) Isolation and characterization of lipid rafts with different properties from RBL-2H3 (rat basophilic leukemia) cells. Biochem. J. 380, 219-230

9 Koumanov, K. S., Tessier, C., Momchilova, A. B., Rainteau, D., Wolf, C. and Quinn, P. J. (2005) Comparative lipid analysis and structure of detergent-resistant membrane raft fractions isolated from human and ruminant erythrocytes. Arch. Biochem. Biophys. 434, 150-158

10 Pike, L. J., Han, X., Chung, K. N. and Gross, R. W. (2002) Lipid rafts are enriched in arachidonic acid and plasmenylethanolamine and their composition is independent of caveolin-1 expression: a quantitative electrospray ionization/mass spectrometric analysis. Biochemistry 41, 2075-2088

11 Schuck, S., Honsho, M., Ekroos, K., Shevchenko, A. and Simons, K. (2003) Resistance of cell membranes to different detergents. Proc. Natl. Acad. Sci. U.S.A. 100, 5795-5800

12 Chen, X., Morris, R. J., Lawrence, M. J. and Quinn, P. J. (2007) The Isolation and Structure of Membrane Lipid Rafts from Rat Brain. Biochimie 89, 192-196

13 Lewis, R. N. and McElhaney, R. N. (2000) Surface charge markedly attenuates the nonlamellar phase-forming propensities of lipid bilayer membranes: calorimetric and (31)P-nuclear magnetic resonance studies of mixtures of cationic, anionic, and zwitterionic lipids. Biophys. J. 79, 1455-1464

14 Li, X. and Schick, M. (2000) Theory of lipid polymorphism: application to phosphatidylethanolamine and phosphatidylserine. Biophys. J. 78, 34-46

15 Papahadjopoulos, D., Poste, G., Schaeffer, B. E. and Vail, W. J. (1974) Membrane fusion and molecular segregation in phospholipid vesicles. Biochim. Biophys. Acta 352, 10-28

16 Cullis, P. R. and Verkleij, A. J. (1979) Modulation of membrane structure by Ca2+ and dibucaine as detected by $31 \mathrm{P}$ NMR. Biochim. Biophys. Acta 552, 546-551

17 Duzgunes, N., Wilschut, J., Fraley, R. and Papahadjopoulos, D. (1981) Studies on the mechanism of membrane fusion. Role of head-group composition in calcium- and magnesium-induced fusion of mixed phospholipid vesicles. Biochim. Biophys. Acta 642, 182-195

18 Tilcock, C. P. and Cullis, P. R. (1981) The polymorphic phase behaviour of mixed phosphatidylserinephosphatidylethanolamine model systems as detected by 31P-NMR. Biochim. Biophys. Acta 641, 189-201

19 Tokutomi, S., Lew, R. and Ohnishi, S. (1981) Ca2+-induced phase separation in phosphatidylserine, phosphatidylethanolamine and phosphatidylcholine mixed membranes. Biochim. Biophys. Acta 643, $276-282$

20 Bakht, O., Pathak, P. and London, E. (2007) Effect of the structure of lipids favoring disordered domain formation on the stability of cholesterol-containing ordered domains (lipid rafts): identification of multiple raft-stabilization mechanisms. Biophys. J. 93, 4307-4318

21 Bally, M. B., Tilcock, C. P., Hope, M. J. and Cullis, P. R. (1983) Polymorphism of phosphatidylethanolaminephosphatidylserine model systems: influence of cholesterol and $\mathrm{Mg} 2+$ on $\mathrm{Ca} 2+$-triggered bilayer to hexagonal (HII) transitions. Can. J. Biochem. Cell Biol. 61, 346-352

22 Martoglio, B., Hauser, S. and Dobberstein, B. (1998) Co-translation of proteins into microsomes derived from the rough endoplasmic reticulum of mammalian cells. In Cell Biology. A laboratory handbook. (Cellis, J. E., ed.). pp. 265-273, Academic Press, Aarhus

23 Trauble, H. and Eibl, H. (1974) Electrostatic effects on lipid phase transitions: membrane structure and ionic environment. Proc. Natl. Acad. Sci. U.S.A. 71, 214-219

24 Brügger, B., Graham, C. H., Leibrecht, I., Mombelli, E., Jen, A., Wieland, F. T. and Morris, R. J. (2004) The membrane domains occupied by glycosylphosphatidylinositol-anchored prion protein and Thy-1 differ in lipid composition. J. Biol. Chem. 279, 7530-7536

25 Sunyach, C., Jen, A., Deng, J., Fitzgerald, K., Frobert, Y., McCaffrey, M. and Morris, R. J. (2003) The mechanism of internalisation of GPI anchored prion protein. EMBO J. 22, 3591-3601

26 Drevot, P., Langlet, C., Guo, X. J., Bernard, A. M., Colard, O., Chauvin, J. P., Lasserre, R. and He, H. T. (2002) TCR signal initiation machinery is pre-assembled and activated in a subset of membrane rafts. EMBO J. 21, 1899-1908

27 Pike, L. J., Han, X. and Gross, R. W. (2005) Epidermal growth factor receptors are localized to lipid rafts that contain a balance of inner and outer leaflet lipids: a shotgun lipidomics study. J. Biol. Chem. 280, 26796-26804

28 Parkyn, C. J., Vermeulen, E. G., Mootoosamy, R. C., Sunyach, C., Jacobsen, C., Oxvig, C., Moestrup, S., Liu, Q., Bu, G., Jen, A. and Morris, R. J. (2008) LRP1 controls biosynthetic and endocytic trafficking of neuronal prion protein. J. Cell Sci. 121, 773-783

29 Laemmli, U. (1970) Cleavage of structural proteins during the assembly of bacteriophage T4. Nature 227, 680-681 
30 Warisnoicharoen, W., Lansley, A. B. and Lawrence, M. J. (2000) Light scattering investigations on dilute nonionic oilin-water microemulsions. A.A.P.S. PharmSci. 2, E12

31 Aussenac, F., Tavares, M. and Dufourc, E. J. (2003) Cholesterol dynamics in membranes of raft composition: a molecular point of view from $2 \mathrm{H}$ and $31 \mathrm{P}$ solid-state NMR. Biochemistry 42, 1383-1390

32 Chachaty, C., Rainteau, D., Tessier, C., Quinn, P. J. and Wolf, C. (2005) Building up of the liquid-ordered phase formed by sphingomyelin and cholesterol. Biophys. J. 88, 4032-4044

33 Tartakoff, A. M. and Vassalli, P. (1983) Lectin-binding sites as markers of Golgi subcompartments: proximal-to-distal maturation of oligosaccharides. J. Cell. Biol. 97, 1243-1248

34 Scott, B. S. (1977) Adult mouse dorsal root ganglia neurons in cell culture. J. Neurobiol. 8, 417-427

35 Ford, M. L., Burton, L. J., Li, H., Graham, C. H., Frobert, Y., Grassi, J., Hall, S. M. and Morris, R. J. (2002) A marked disparity between the expression of prion protein and its message by neurons of the central nervous system.

Neuroscience 111, 533-551

36 Morris, R. (1992) Thy-1, the enigmatic extrovert on the neuronal surface. BioEssays 14, 715-722

37 Morris, R. J., Parkyn, C. J. and Jen, A. (2006) Traffic of prion protein between different compartments on the neuronal surface, and the propagation of prion disease. FEBS Lett. 580, 5565-5571

38 Morris, R., Cox, H., Mombelli, E. and Quinn, P. J. (2004) Rafts, little caves and large potholes: how lipid structure interacts with membrane proteins to create functionally diverse membrane environments. Subcell. Biochem. 37, 35-118

39 Buchser, W. J., Pardinas, J. R., Shi, Y., Bixby, J. L. and Lemmon, V. P. (2006) 96-well electroporation method for transfection of mammalian central neurons. Biotechniques 41, 619-624

40 Hueber, A. O., Bernard, A. M., Battari, C. L., Marguet, D., Massol, P., Foa, C., Brun, N., Garcia, S., Stewart, C., Pierres, M. and He, H. T. (1997) Thymocytes in Thy-1-/- mice show augmented TCR signaling and impaired differentiation. Curr. Biol. 7, 705-708

41 Holowka, D., Gosse, J. A., Hammond, A. T., Han, X., Sengupta, P., Smith, N. L., Wagenknecht-Wiesner, A., Wu, M., Young, R. M. and Baird, B. (2005) Lipid segregation and IgE receptor signaling: A decade of progress. Biochim. Biophys. Acta 1746, 25209

42 Viola, A. and Gupta, N. (2007) Tether and trap: regulation of membrane-raft dynamics by actin-binding proteins. Nat. Rev. Immunol. 7, 889-896

43 Stuermer, C. A., Langhorst, M. F., Wiechers, M. F., Legler, D. F., Von Hanwehr, S. H., Guse, A. H. and Plattner, H. (2004) PrPc capping in T cells promotes its association with the lipid raft proteins reggie-1 and reggie-2 and leads to signal transduction. FASEB J. 18, 1731-1733

44 Staneva, G., Seigneuret, M., Koumanov, K., Trugnan, G. and Angelova, M. I. (2005) Detergents induce raft-like domains budding and fission from giant unilamellar heterogeneous vesicles: a direct microscopy observation. Chem Phys Lipids. 136, 55-66

45 Zimmerberg, J. (2000) Are the curves in all the right places? Traffic 1, 366-368

46 Paar, J. M., Harris, N. T., Holowka, D. and Baird, B. (2002) Bivalent ligands with rigid double-stranded DNA spacers reveal structural constraints on signaling by Fc epsilon RI. J. Immunol. 169, 856-864

47 Suzuki, K. G., Fujiwara, T. K., Edidin, M. and Kusumi, A. (2007) Dynamic recruitment of phospholipase C gamma at transiently immobilized GPI-anchored receptor clusters induces IP3-Ca2+ signaling: single-molecule tracking study 2 . J. Cell Biol. 177, 731-742

48 Suzuki, K. G., Fujiwara, T. K., Sanematsu, F., Iino, R., Edidin, M. and Kusumi, A. (2007) GPI-anchored receptor clusters transiently recruit Lyn and $\mathrm{G}$ alpha for temporary cluster immobilization and Lyn activation: single-molecule tracking study 1. J. Cell Biol. 177, 717-730

49 Harder, T., Scheiffele, P., Verkade, P. and Simons, K. (1998) Lipid domain structure of the plasma membrane revealed by patching of membrane components. J. Cell Biol. 141, 929-942

50 Lenne, P. F., Wawrezinieck, L., Conchonaud, F., Wurtz, O., Boned, A., Guo, X. J., Rigneault, H., He, H. T. and Marguet, D. (2006) Dynamic molecular confinement in the plasma membrane by microdomains and the cytoskeleton meshwork. EMBO J. 25, 3245-3256

51 Wenger, J., Conchonaud, F., Dintinger, J., Wawrezinieck, L., Ebbesen, T. W., Rigneault, H., Marguet, D. and Lenne, P. F. (2007) Diffusion analysis within single nanometric apertures reveals the ultrafine cell membrane organization. Biophys. J. 92, 913-919

52 Ge, M., Gidwani, A., Brown, H. A., Holowka, D., Baird, B. and Freed, J. H. (2003) Ordered and disordered phases coexist in plasma membrane vesicles of RBL-2H3 mast cells. An ESR study. Biophys. J. 85, 1278-1288

53 Swamy, M. J., Ciani, L., Ge, M., Smith, A. K., Holowka, D., Baird, B. and Freed, J. H. (2006) Coexisting domains in the plasma membranes of live cells characterized by spin-label ESR spectroscopy. Biophys. J. 90, 4452-4465 


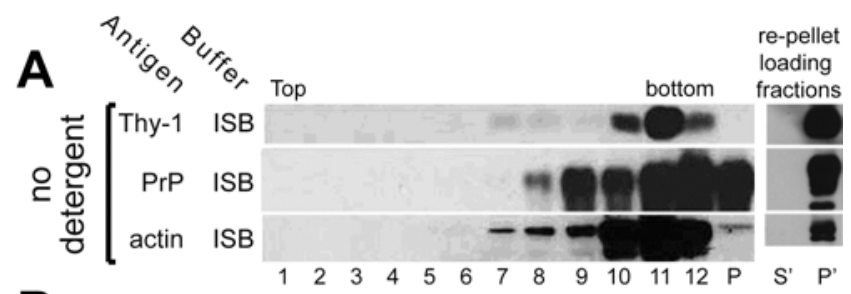

B
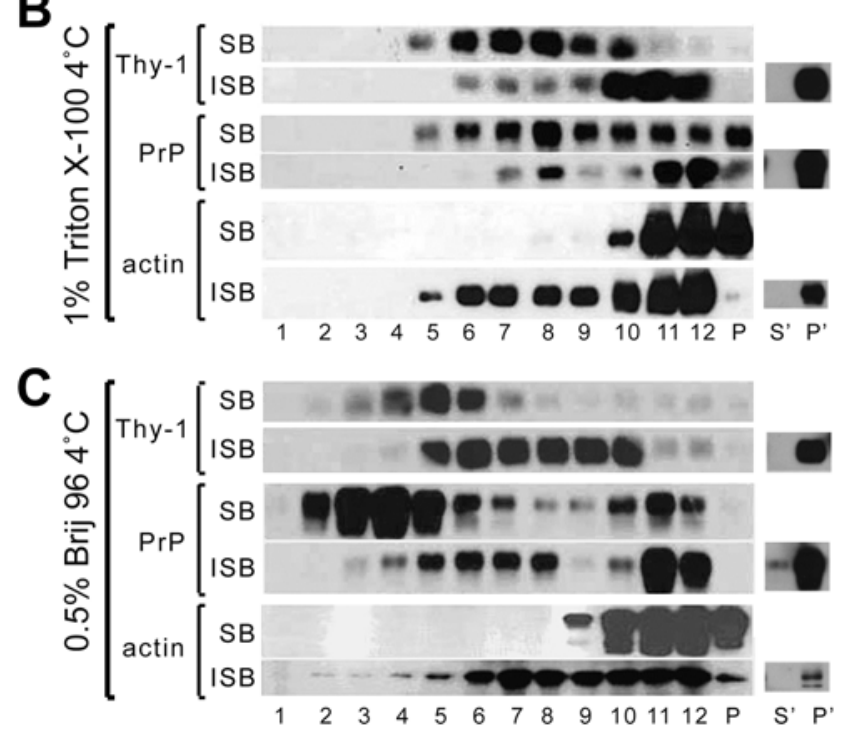

Figure 1. Immunoblots of protein distribution on sucrose density gradients following solubilisation of brain membranes at $4^{\circ} \mathrm{C}$

(A) shows Thy-1, PrP and actin on membranes without solubilization, with the top (fraction 1) and bottom (fraction 12) of the gradient indicated; the pellet at the bottom of the gradient $(\mathrm{P})$ was resuspended in $1 \mathrm{ml}$ of buffer (ISB). The panel to the right shows an immunoblot of supernatant (S') and pellet $\left(\mathrm{P}^{\prime}\right)$ fractions after the loading fractions $(11+12)$ were combined, diluted to $8 \%$ sucrose and re-centrifuged at $45,000 \mathrm{~g}$ for $3 \mathrm{hr}$.

(B) and (C) show the distribution of these proteins following solubilization of the brain membranes for 15 min in Triton X-100 (B) or Brij 96 (C), with the right hand panels showing the supernatant and pellet fractions after dilution and centrifugation as above. 


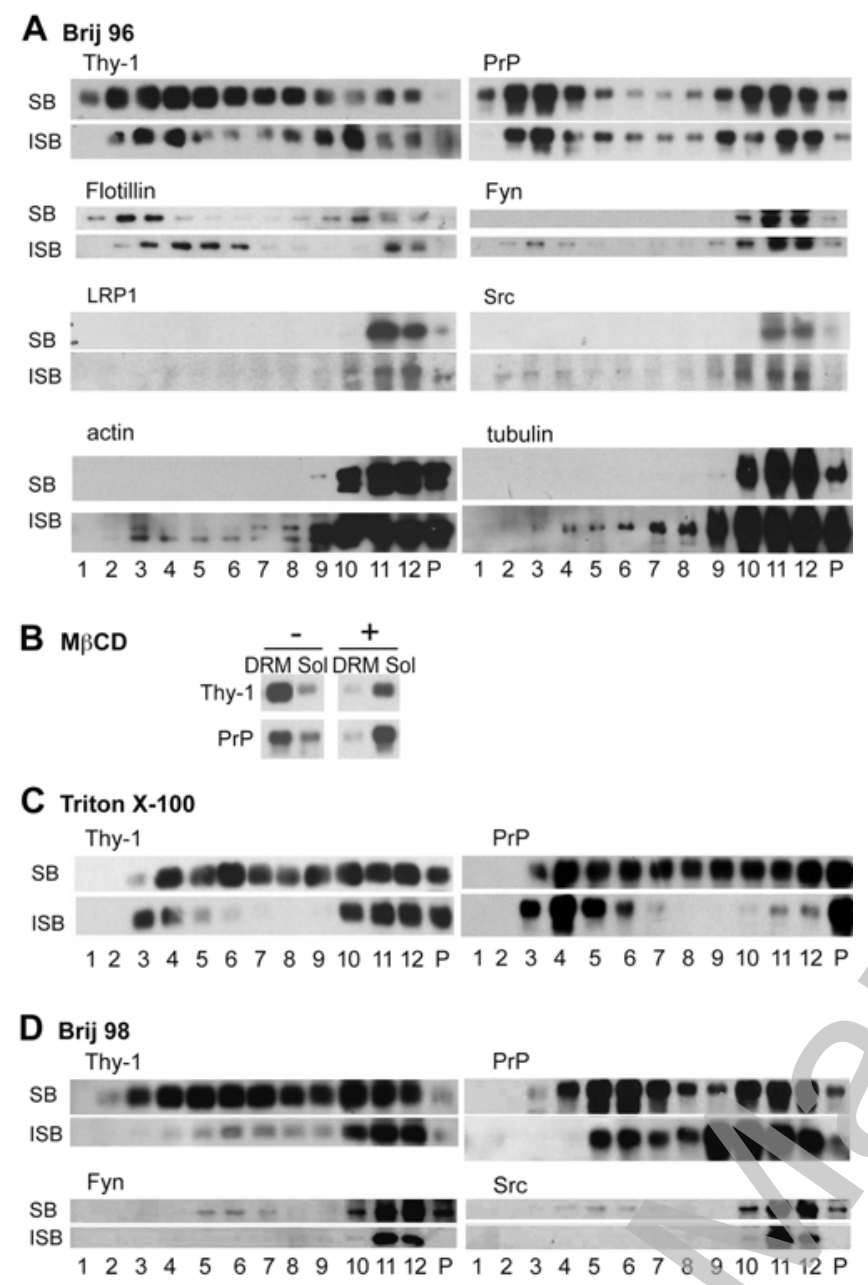

Figure 2. Immunoblots of protein distribution on sucrose density gradients following solubilisation of brain membranes at $37^{\circ} \mathrm{C}$

(A) shows the distribution of a range of proteins (fraction 1, top, fractions 11,12 the bottom loading fractions; P, resuspended pellet) following solubilization in Brij 96 for 5 min. (B) Effect of depleting the membranes of cholesterol by chelation with $5 \mathrm{mM} \mathrm{MBCD}$ for $30 \mathrm{~min}$ at $37^{\circ} \mathrm{C}$ prior to solubilization in Brij 96, shown by immunoblots for Thy-1 and PrP of pooled DRM fractions 2-4 and pooled solubilised (Sol) fractions 11+12. (C) shows the distribution of Thy-1 and PrP after solubilization of membranes in $1 \%$ Triton $\mathrm{X}-100$ for $5 \mathrm{~min}$ at $37^{\circ} \mathrm{C}$, and (D) the distribution of the proteins shown after solubilization in $1 \%$ Brij 98 for $15 \mathrm{~min}$ at $37^{\circ} \mathrm{C}$. 


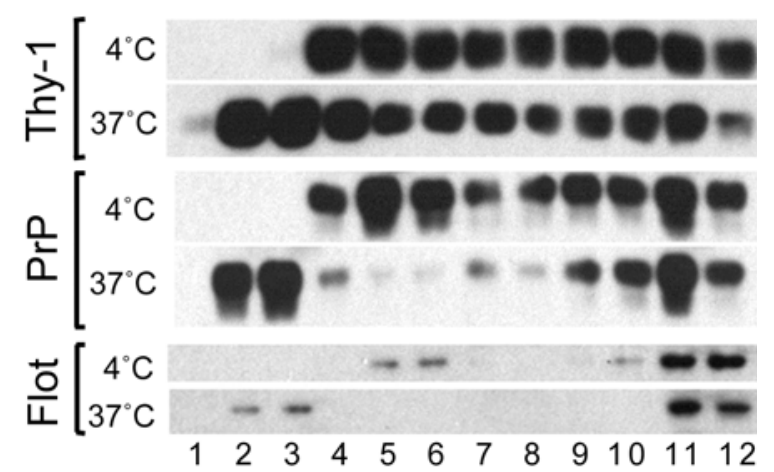

Figure 3. Stability of DRMs to isolation at $37^{\circ} \mathrm{C}$ including during their $18 \mathrm{hr}$ gradient ultracentrifugation

Brain membranes were solubilized for 5 min at $37^{\circ} \mathrm{C}$ in $1 \%$ Triton $\mathrm{X}-100$ in ISB, and then incorporated into a sucrose gradient and ultracentrifuged at either $4^{\circ} \mathrm{C}$ or $37^{\circ} \mathrm{C}$ as indicated. Immunoblots of samples recovered from the gradients are for Thy-1, PrP and Flotillin-1 (Flot).

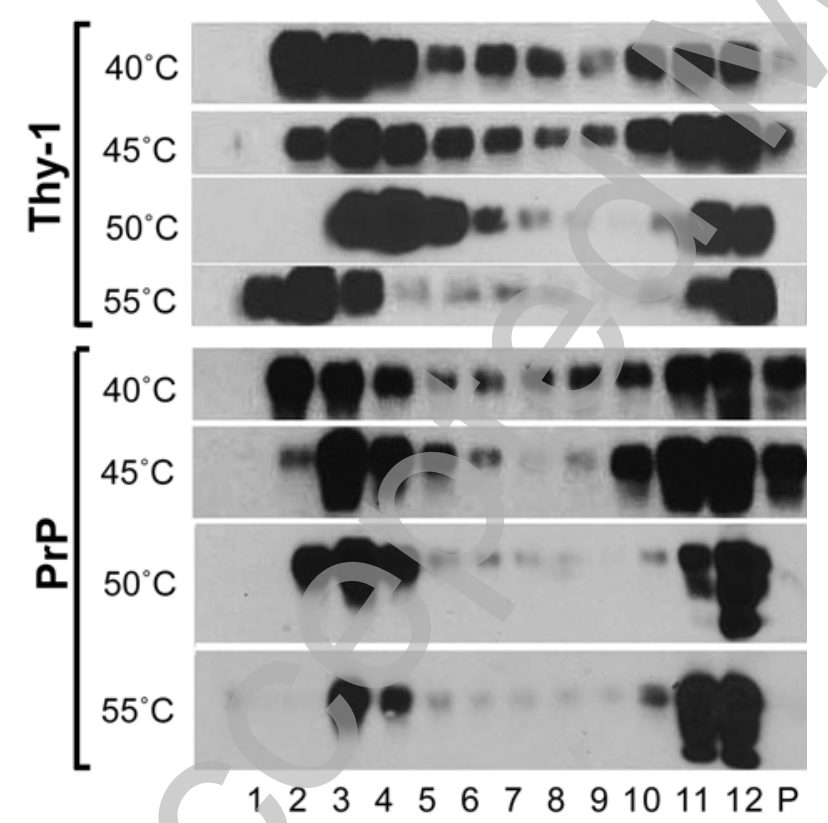

Figure 4. Effect on increasing temperatures of solubilization by Triton X-100

Immunoblots show the distribution of Thy- 1 and PrP along sucrose gradients after solublization of brain membranes in $1 \%$ Triton X-100 in ISB for 5 min at the temperature shown, 


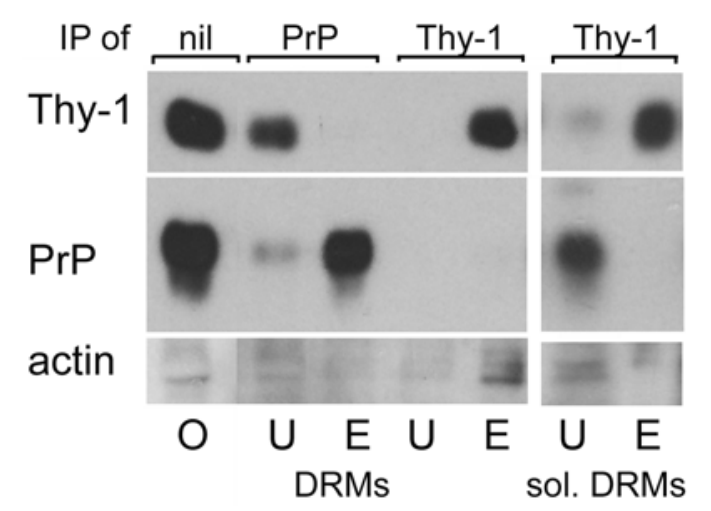

Figure 5. Separate immunoprecipitation of PrP and Thy-1 from brain membranes after solubilization in Brij 96 at $37^{\circ} \mathrm{C}$

Serial immunoprecipitation (IP) of PrP followed by Thy-1 DRMs from gradient fractions 3+4, after brain membranes were solubilized in $0.5 \%$ Brij 96 in ISB at $37^{\circ} \mathrm{C}$ for 5 min; right panel shows IP for Thy-1 from DRMs that have been fully solubilized (sol) in $5 \%$ sodium deoxycholate at $37^{\circ} \mathrm{C}$ for 15 min. O: original DRM fraction prior to IP; U: unbound antigen after IP; E: antigen bound and eluted.

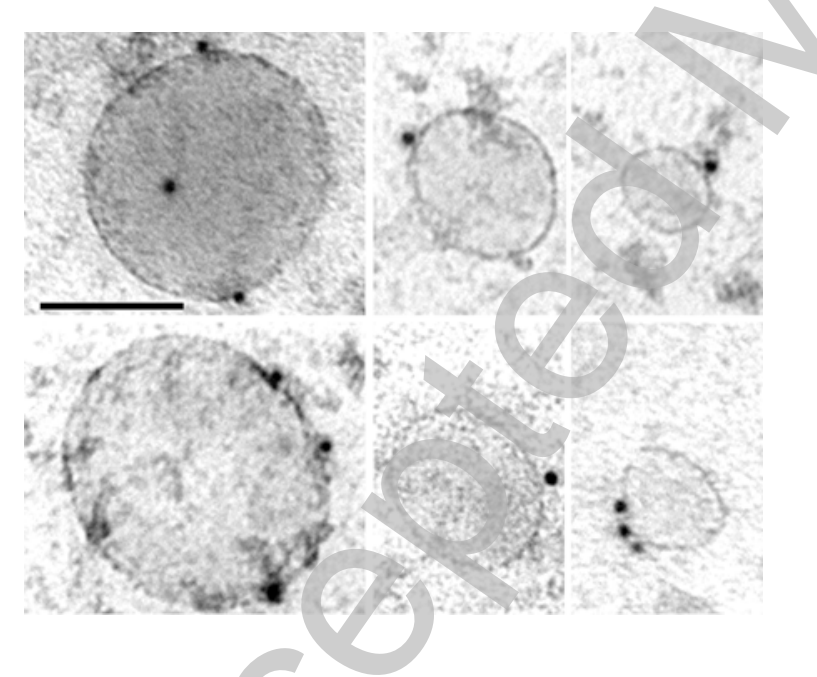

Figure 6. Glycoproteins are only on the outer face of DRMs isolated at $37^{\circ} \mathrm{C}$ in Brij 96/ISB Cryo-EM sections labelled with WGA-5nm gold. Scale bar is $100 \mathrm{~nm}$. 


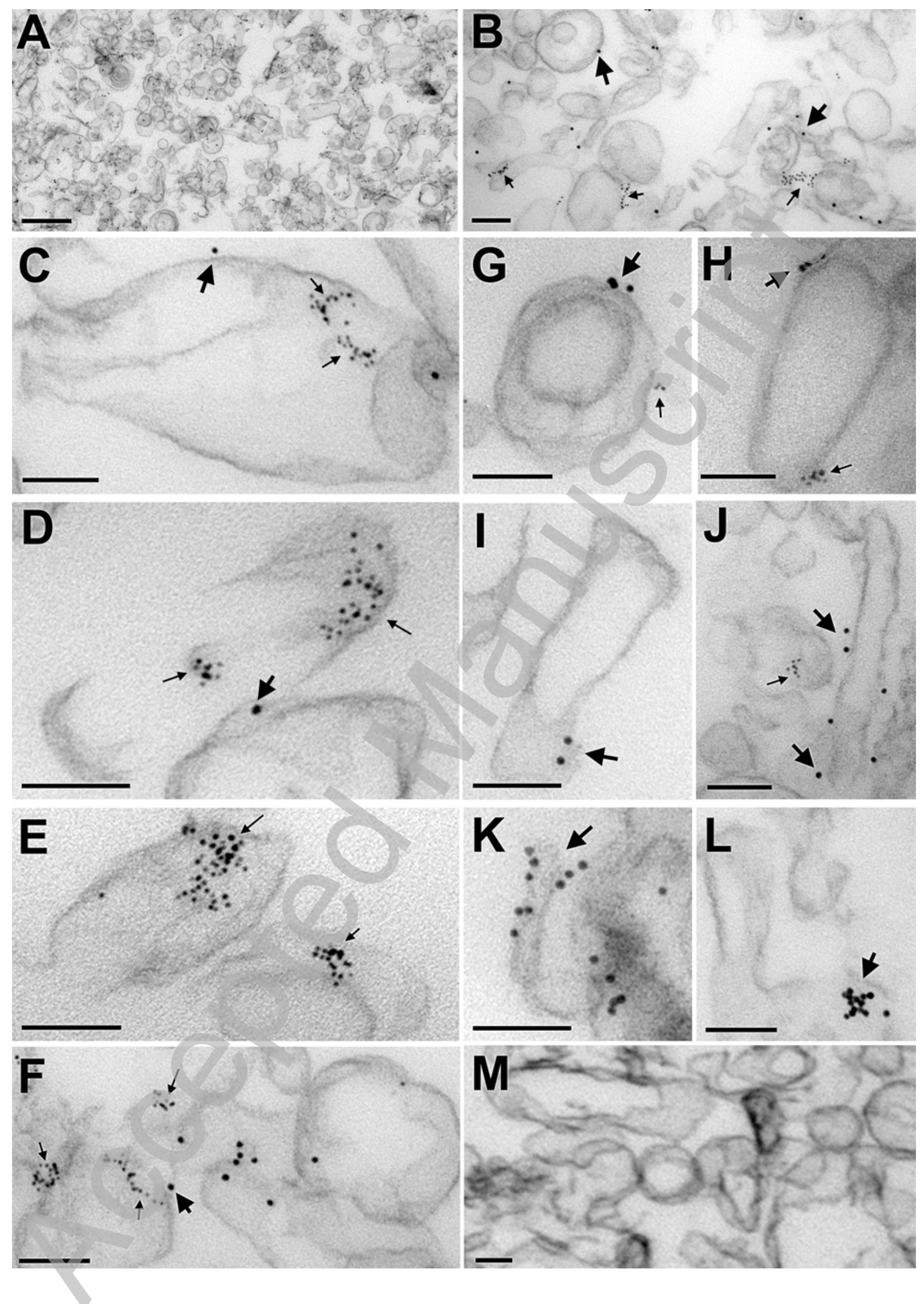

Fig 7. Thy-1 and PrP localization on $37^{\circ} \mathrm{C}$ Brij 96 DRMs.

DRMs isolated by solubilization in $0.5 \%$ Brij $96 / \mathrm{ISB}$ at $37^{\circ} \mathrm{C}$, were immunolabelled for $30 \mathrm{~min}$ at $37^{\circ} \mathrm{C}$ with $5 \mathrm{~nm}$ gold-Fab for PrP (small arrows) and $10 \mathrm{~nm}$ gold-Fab for Thy-1 (large arrows) (A-L). As a negative control (M), antibodies specific for human PrP and mouse Thy-1 coupled to 5 and $10 \mathrm{~nm}$ gold respectively were used to immunolabel the same rat DRM preparation; neither antibody labelled the DRMs. Scale bars are $500 \mathrm{~nm}(\mathrm{~A})$, elsewhere $100 \mathrm{~nm}$. 


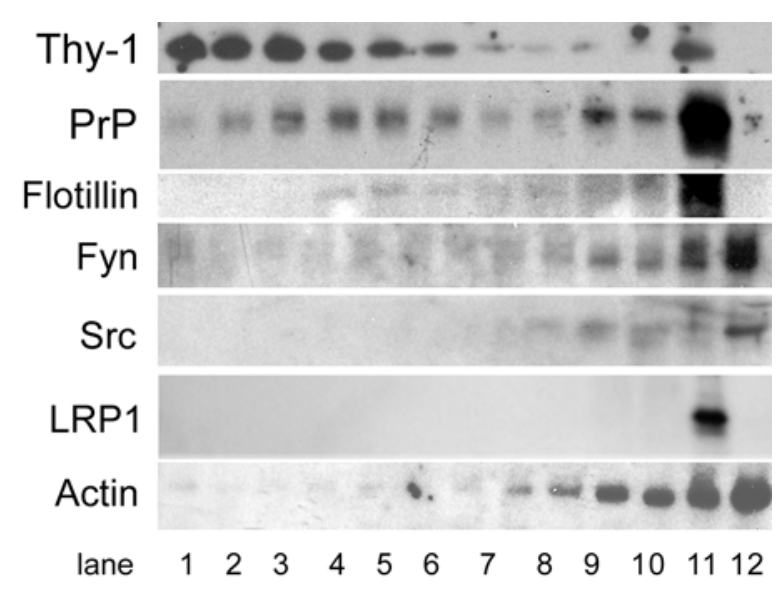

\section{Figure 8. Isolation of DRMs from cultured adult sensory neurons}

Cell membranes could only be obtained at $0.5 \mathrm{mg} / \mathrm{ml}$ of membrane protein, and so were solubilized in ISB at $37^{\circ} \mathrm{C}$ in $0.05 \%$ Brij 96, to maintain the same detergent:protein ratio as used with brain membranes. Immunoblots are of fractions along the gradient as before, fraction 12 is the pellet.

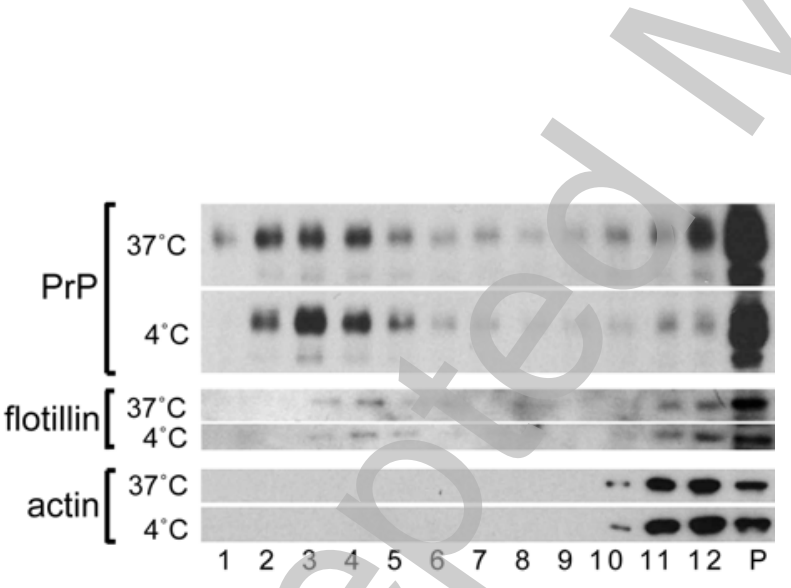

Figure 9. Immunoblots to demonstrate the release of DRMs from N2a cell membranes

Solublization was of $5 \mathrm{mg}$ protein $/ \mathrm{ml}$ by $0.05 \%$ Brij 96 in ISB, at $37^{\circ} \mathrm{C}$ for $5 \mathrm{~min}$, or $4^{\circ} \mathrm{C}$ for $15 \mathrm{~min}$; $\mathrm{P}$ indicates the pellet fraction. 